\title{
Low-intensity inspiratory loaded exercises improve physical health perception in women with type 2 diabetes
}

\author{
DOI: https://doi.org/10.5114/pq.2020.92472
}

\author{
Ahmad Mahdi Ahmad', Heba Mohammed Ali² \\ ${ }^{1}$ Department of Physical Therapy for Cardiovascular and Respiratory Disorders, Faculty of Physical Therapy, \\ Cairo University, Giza, Egypt \\ ${ }^{2}$ Department of Physical Therapy for Internal Medicine, Faculty of Physical Therapy, Beni-Suef University, Beni Suef, \\ Egypt
}

\section{Abstract}

Introduction. Physical exercises improve quality of life in type 2 diabetes. Inspiratory muscle exercises may be an alternative option for diabetic patients with physical disabilities unable to engage in physical exercises. The purpose of this study was to investigate the effect of inspiratory muscle exercises on physical and mental health dimensions of the 12-Item Short Form (SF-12) Health Survey in women with type 2 diabetes.

Methods. Overall, 26 women with type 2 diabetes were allocated to the control $(n=14)$ or study group $(n=12)$. They were obese, aged 30-55 years, receiving oral hypoglycaemic medications. The inspiratory loaded exercise target intensity was $30 \%$ of maximal inspiratory pressure; sessions lasting 15-25 min were held on 5 days per week for 8 weeks. Quality of life was assessed as a primary outcome with the SF-12 questionnaire. Fasting and 2-hour postprandial blood glucose levels were measured as secondary outcomes.

Results. Compared with the control group, significant improvements were observed in the study group after the intervention in all SF-12 physical health domains and in SF-12 role emotional and social functioning mental health domains. In addition, fasting blood glucose was reduced from $134 \pm 40$ to $126.8 \pm 51 \mathrm{mg} / \mathrm{dl}$, which was a non-statistically but clinically significant change. Conclusions. Low-intensity inspiratory loaded exercises could be viewed as a successful alternative to physical exercises in improving physical quality of life in type 2 diabetic women. Health professionals interested in exercise therapy for type 2 diabetes may consider our findings.

Key words: type 2 diabetes, inspiratory loaded exercises, physical health, women, SF-12

\section{Introduction}

In 2018 , over 500 million cases of type 2 diabetics were reported worldwide, with the greatest prevalence in countries of lower income [1]. Type 2 diabetes, as a complex chronic illness, has a continuously negative impact on the patients' quality of life (QoL) [2]. The ultimate aim of type 2 diabetes management plans is to enhance the health-related QoL by using both drug and non-drug therapy. Aerobic exercise, as a non-drug intervention, can effectively improve QoL in patients with type 2 diabetes [3]. However, not all patients with type 2 diabetes have the ability to perform physical exercises because of neurological, musculoskeletal, or vascular problems in the lower limbs. Therefore, other types of exercise are required in these cases.

Inspiratory muscle exercise training is most commonly implemented in pulmonary rehabilitation programs as an evidence-based intervention [4]; it can also be applied in different clinical settings. Inspiratory muscle exercises have been effective in enhancing QoL of different patient populations [5-10]. Two recent meta-analysis studies emphasized the role of inspiratory muscle exercise training in improving QoL in patients with heart failure [11] and those with chronic obstructive pulmonary disease [12]. QoL can be assessed by the 12-Item Short Form (SF-12) Health Survey, considered as a validated generic instrument to evaluate physical and mental QoL in patients with diabetes [13]. Therefore, the main purpose of this study was to investigate the effect of inspi- ratory muscle loaded exercise, as a substitute for physical exercise, on diabetes-related QoL assessed with the SF-12 questionnaire in female patients with type 2 diabetes. The results of the research may aid health professionals involved in diabetes care in recognizing new alternatives of exercise therapy that could be included in the type 2 diabetes management plan.

\section{Subjects and methods}

\section{Subjects}

A total of 28 women with type 2 diabetes were selected from the Om Al-Masryeen General Hospital in Giza, Egypt and were assigned for the research. The inclusion criteria were type 2 diabetics, obesity, age of 30-55 years, and receiving oral hypoglycaemic medications. Exclusion criteria were type 1 diabetics, male sex, pregnancy, receiving insulin therapy, taking part in other physical exercise programs, chest problems, other hormonal abnormalities, and neurological disorders affecting respiratory muscles. The participants eligible for the study were equally assigned to 2 groups: the control group $\left(n_{1}=14\right)$ that received medical treatment only and the study group $\left(n_{2}=14\right)$ that was under medical treatment plus inspiratory muscle loaded exercises. In the study group, two patients dropped out and 12 participants adhered well to the treatment sessions throughout the 8-week period of intervention. In the control group, all patients com- 
pleted the SF-12 Health Survey and only one patient missed blood glucose analysis. The inspiratory muscle exercises were supervised, except for two patients who practised their exercises at home and were checked for compliance by telephone calls. The baseline anthropometric and clinical characteristics of the patients are presented in Table 1.

\section{Measurements}

\section{Demographic and anthropometric measures}

The subjects' age, body weight (BW), and height were determined. Body mass index (BMI) was calculated in accordance with the following formula: $\mathrm{BMI}=\mathrm{BW}[\mathrm{kg}] / \mathrm{height}^{2}\left[\mathrm{~m}^{2}\right]$.

\section{Maximal inspiratory pressure}

Maximal inspiratory pressure (MIP) was measured at the beginning of the study to determine the target intensity of the inspiratory muscle exercises. A simple technique was used for the MIP measurement: the patients were asked to breathe in deeply through a tube connected to an aneroid manometer. They had their nose clipped and were instructed to seal the lips firmly around the tube to prevent leakage of air. The maximum negative pressure generated by the patients and recorded by the manometer gauge showed MIP [14-16].

\section{The 12-Item Short Form Health Survey (primary outcome)}

SF-12 has been recommended for evaluation of physical and mental QoL in diabetic subjects [17]. It is a short-form questionnaire that was developed from the original 36-Item Short Form Health Survey as a shorter and validated version [18]. SF-12 can assess physical and mental QoL among many patient populations in clinical and research settings. It comprises 12 items covering the same physical and mental domains as SF-36 but with more answer choices covering a wider range of health states [18]. Physical health domains include physical functioning, role physical, and bodily pain. Mental health scales are vitality, social functioning, role emotional, and mental health [18]. The SF-12 Arabic version translated from the English version was used in the study, in accordance with Al-Shehri et al. [19]. The physiotherapist administered and recorded the SF-12 questionnaires through face-to-face interviews with the patients. SF-12 scoring was done in accordance with Micholas [20], and reverse scoring was needed in 4 items so that higher scores showed better health status for all domains. The score of each domain was then transformed to a linear scale that ranged from 0 to 100 [21].

\section{Blood analysis (secondary outcome)}

Fasting blood glucose and 2-hour postprandial blood glucose were measured before and after the intervention. Baseline glycosylated haemoglobin $\left(\mathrm{HbA}_{1 \mathrm{c}}\right)$ was determined for all patients.

Treatment intervention (the inspiratory loaded exercises)

The treatment intervention was conducted in the Diabetes Outpatient Clinic at Om Al-Masryeen General Hospital in Giza, Egypt. The inspiratory loaded exercises focused on spiratory muscle trainer (Threshold IMT ${ }^{\circledR}$, Koninklijke Philips Electronics N.V., China) and were performed under the supervision of a physiotherapist. The inspiratory muscle exercise prescription was individualized for each patient and was developed in accordance with the recommendations by Cipriano et al. [22], as follows: the target exercise intensity was set at a load of $30 \%$ of the baseline MIP, the frequency of sessions was once daily for 5 days per week, the session time ranged from 10 to 25 minutes throughout the intervention. In the first 2 weeks, to familiarize the patients with the respiratory training, a session time of $10-15$ minutes ( 5 sets $\times 20$ breaths/set) was permitted. Then, the duration was increased progressively to $15-20$ minutes ( 5 sets $\times 30$ breaths/ set) for the next 3 weeks and to $20-25$ minutes $(8$ sets $\times 30$ breaths/set) for the rest of the intervention. The intervention duration was 8 weeks. During the sessions, the patients were encouraged to breathe slowly and deeply in a diaphragmatic pattern of breathing and were allowed to rest for 2 minutes between the sets.

\section{Statistical analysis}

Both parametric and non-parametric statistics were used for data analysis. Regarding anthropometric and biochemical blood analysis data, an unpaired $t$-test was used to check for any significant differences between the 2 groups, and a paired $t$-test was applied to verify any significant changes within the same group. As for the SF-12 Health Survey scores, MannWhitney $U$ test was used to assess significant differences between the 2 groups at the beginning of and after the intervention. Wilcoxon signed-rank test served to evaluate significant changes within each group after the intervention. Data were presented as means \pm standard deviation and as medians and interquartile range. Only $p$ values of less than 0.05 were considered statistically significant. Statistical analysis was performed by using the GraphPad Prism and Statistical Social Science software. Statistical analysis was carried out only for patients who completed the study (i.e. $n_{1}=14, n_{2}=12$ ). Because 1 patient in the control group missed blood glucose measurement, statistical analysis of blood glucose variables included only 13 patients in the control group (i.e. $n_{1}=13$, $\left.n_{2}=12\right)$.

\section{Ethical approval}

The research related to human use has complied with all the relevant national regulations and institutional policies, has followed the tenets of the Declaration of Helsinki, and has been approved by the Ethics Committee of Scientific Research of the Faculty of Physical Therapy, Cairo University.

\section{Informed consent}

Informed consent has been obtained from all individuals included in this study.

\section{Results}

Table 1 shows the baseline anthropometric and clinical characteristics of the patients in the 2 groups. Baseline SF-12 Health Survey scores are shown in Table 2. At baseline, no significant differences were observed between the 2 groups in any of the measured variables. As shown in Table 3 and Figure 1, upon the comparison between the 2 groups after the intervention, there were significant differences in all SF-12 physical health domains and 2 of the mental health domains, namely, role emotional and social functioning domains. In the study group, there were significant improvements in SF-12 
Table 1. Baseline anthropometric and clinical characteristics

\begin{tabular}{|c|c|c|c|}
\hline Variables & Control group $\left(n_{1}=14\right)$ & Study group $\left(n_{2}=14\right)$ & $p$ \\
\hline Age (years) & $44.3 \pm 7$ & $42.2 \pm 6$ & 0.40 \\
\hline Height (cm) & $155 \pm 7$ & $156 \pm 6$ & 0.67 \\
\hline Body weight (kg) & $89.2 \pm 13$ & $84.6 \pm 13$ & 0.35 \\
\hline BMI $\left(\mathrm{kg} / \mathrm{m}^{2}\right)$ & $36.8 \pm 5.7$ & $34.6 \pm 4.6$ & 0.18 \\
\hline Duration of diabetes (years) & $2.9 \pm 3.4$ & $4 \pm 3$ & 0.386 \\
\hline $\mathrm{FBG}(\mathrm{mg} / \mathrm{dl})$ & $145.3 \pm 46.7$ & $134.9 \pm 37.3$ & 0.52 \\
\hline 2HPP blood glucose (mg/dl) & $217.4 \pm 102.8$ & $201 \pm 59.24$ & 0.62 \\
\hline $\mathrm{HbA}_{1 \mathrm{c}}(\%)$ & $6.75 \pm 1.21$ & $6.65 \pm 1.16$ & 0.83 \\
\hline
\end{tabular}

Data are expressed as means \pm standard deviation.

$\mathrm{BMI}$ - body mass index, FBG - fasting blood glucose, $2 \mathrm{HPP}$ - 2-hour postprandial, $\mathrm{HbA}_{1 \mathrm{c}}$ - glycosylated haemoglobin

Table 2. Baseline SF-12 scores

\begin{tabular}{|l|c|c|}
\hline SF-12 domains & Control group $\left(n_{1}=14\right)$ & Study group $\left(n_{2}=14\right)$ \\
\hline Physical functioning (\%) & $25(0-56.25)$ & $50(18.75-50)$ \\
\hline Role physical (\%) & $0(0-100)$ & $12.5(0-100)$ \\
\hline Bodily pain (\%) & $50(43.75-50)$ & $50(43.75-56.25)$ \\
\hline Role emotional (\%) & $0.52-12.5)$ & $50(0-100)$ \\
\hline Mental health (\%) & $40(27.5-60)$ & $50(47.5-80)$ \\
\hline Vitality (\%) & $20(0-45)$ & 0.21 \\
\hline Social functioning (\%) & $25(25-75)$ & $40(20-45)$ \\
\hline
\end{tabular}

The data are expressed as medians and $25^{\text {th }}-75^{\text {th }}$ percentiles.

SF-12 - 12-Item Short Form (SF-12) Health Survey

Table 3. Results of the 2 groups after the intervention

\begin{tabular}{|c|c|c|c|c|}
\hline \multirow{2}{*}{ Variable } & \multicolumn{2}{|c|}{ Control group $\left(n_{1}=14\right)$} & \multicolumn{2}{|c|}{ Study group $\left(n_{2}=12\right)$} \\
\hline & Pre & Post & Pre & Post \\
\hline Physical functioning domain (\%) & $25(0-56.25)$ & $12.5(0-25)$ & $50(25-50)$ & $72.72(50-93.75)^{\star} \mathbb{1}$ \\
\hline Role physical domain (\%) & $0(0-100)$ & $0(0-0)$ & $12.5(0-100)$ & 100 (18.18-100) \\
\hline Bodily pain domain (\%) & $50(43.75-50)$ & $37.5(0-50)$ & $50(50-68.75)$ & $56.81(50-75) \pi$ \\
\hline Role emotional domain (\%) & $0(0-12.5)$ & $0(0-0)$ & $25(0-100)$ & $50(0-100)$ П \\
\hline Mental health domain (\%) & $40(27.5-60)$ & $50(20-55)$ & $50(42.5-80)$ & $55(50-75.22)$ \\
\hline Vitality domain (\%) & $20(0-45)$ & $40(20-60)$ & $40(20-40)$ & $40(40-75)^{\star}$ \\
\hline Social functioning domain (\%) & $25(25-75)$ & $25(18.75-50)$ & $62.5(31.25-100)$ & 75 (75-100)ף \\
\hline Fasting blood glucose $(\mathrm{mg} / \mathrm{dl})\left(n_{1}=13\right)$ & $143.85 \pm 48$ & $133.23 \pm 65$ & $134.08 \pm 40$ & $126.8 \pm 51$ \\
\hline 2-hour postprandial glucose $(\mathrm{mg} / \mathrm{dl})\left(n_{1}=13\right)$ & $220.4 \pm 106$ & $211.9 \pm 90$ & $199 \pm 64$ & $187 \pm 72$ \\
\hline
\end{tabular}

The data are expressed as medians and $25^{\text {th }}-75^{\text {th }}$ percentiles and as means \pm standard deviation.

* Significant difference within the same group (based on the Wilcoxon signed-rank test)

II Significant difference between the 2 groups (based on the Mann-Whitney U test) 


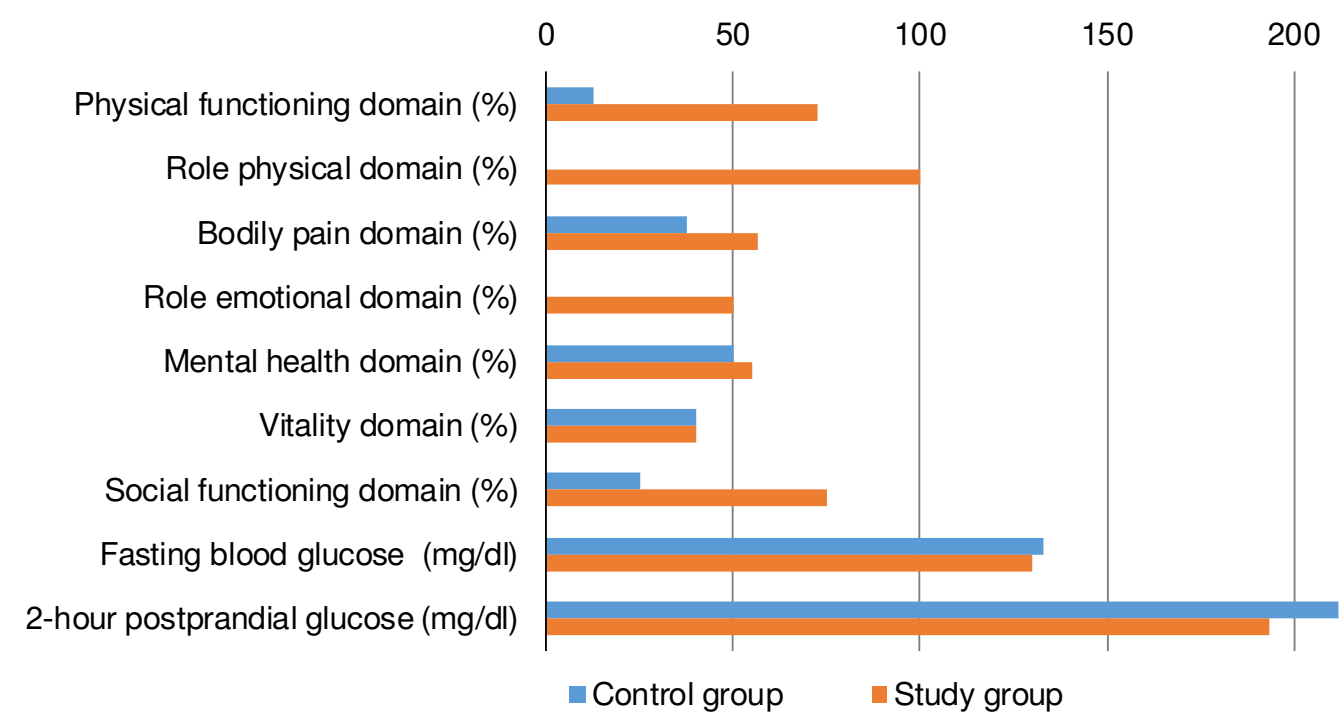

Figure 1.

Comparison between the 2 groups after the intervention physical functioning and vitality domains compared with the baseline values. In addition, a reduction of fasting blood glucose from $134 \pm 40$ to $126.8 \pm 51 \mathrm{mg} / \mathrm{dl}$ was observed in the study group (Table 3 ).

\section{Discussion}

The main purpose of the research was to investigate the effect of inspiratory muscle loaded exercises on diabetesrelated QoL assessed by SF-12 in a sample of type 2 diabetic women. The main findings of the study are the following: (a) Low-intensity inspiratory loaded exercises significantly improved all physical health domains of SF-12, as well as 2 mental health domains, namely role emotional and social functioning domains, in the study group compared with the control group. (b) The physical functioning and vitality domains were improved significantly in the study group compared with the baseline values. (c) Fasting blood glucose decreased from $134 \pm 40$ to $126.8 \pm 51 \mathrm{mg} / \mathrm{dl}$ in the study group. Although this reduction was not statistically significant, it was clinically significant (i.e. a value of $<130 \mathrm{mg} / \mathrm{dl}$ was obtained).

Similarly to our results, inspiratory muscle exercise at $40 \%$ of MIP significantly improved the physical health and mental health dimensions of SF-36 in patients with heart failure [6]. In addition, in heart failure patients, inspiratory muscle exercise practised at low intensity ( $30 \%$ of MIP), produced remarkable improvements in physical but not in psychological dimensions of the Minnesota Living with Heart Failure Questionnaire [5]. One of the main findings in this study was that the inspiratory muscle exercises at a lower intensity $(30 \%$ of MIP) improved the SF-12 physical health domains in women with type 2 diabetes. This can be demonstrated by the significant improvement in the physical functioning domain compared with the baseline value, and by the significant improvements in the physical functioning, role physical, and bodily pain domains compared with the control group after the intervention. The improvement in physical health-related QoL can be explained in several ways: (a) Firstly, the inspiratory loaded exercises improved inspiratory muscle strength and endurance, which resulted in increased respiratory capacity and thus tolerability to fatigue during physical tasks of daily living. This explanation can be supported by the results of several studies, all of which illustrated that low intensity (30\% of MIP) inspiratory muscle exercise significantly improved inspira- with metabolic syndrome [23], heart failure [5], chronic obstructive pulmonary disease [24], and atrial fibrillation [25]. (b) The second explanation is reduced breathless sensation during exertion because of improved inspiratory muscle performance [26]. It has been reported that inspiratory muscle exercise reduces exertional dyspnoea in both healthy and patient populations [27]. (c) The third factor is an increased exercise capacity, walking ability, and physical activity tolerance. This is supported by previous studies which implied that inspiratory muscle exercise loaded at a lower intensity significantly increased walking ability and exercise tolerance as evidenced by a significant increase in 12-minute walk distance in patients with chronic obstructive pulmonary disease [24], as well as a significant improvement in 6-minute walk distance in patients with atrial fibrillation [25] and subacute stroke [28]. (d) Fourthly, inspiratory loaded exercises can improve lung ventilation and diffusion, which enhances pulmonary oxygen uptake $\left(\mathrm{VO}_{2}\right)$ [29]. Enhanced pulmonary oxygen uptake dynamics leads to improvements in oxygen delivery to the working muscles through the cardiovascular system and the transport processes within the muscle tissue [30]. (e) Finally, mitochondrial oxidative capacity was improved after inspiratory exercise training in a manner similar to that after aerobic exercise training [31]. Together with the increased bioavailability of oxygen within the contracting muscles, this leads to enhanced recruitment of the aerobic system, which could reduce skeletal muscle fatigability and increase patients' tolerance to daily physical activities.

Another finding of our study is that the inspiratory muscle exercises additionally produced some benefits in mental health domains among type 2 diabetics. This observation could be demonstrated by the significant improvement in the vitality domain compared with the baseline value and by the significant improvements in the role emotional and social functioning domains compared with the control group after the intervention. This finding can be supported by an earlier study by Bosnak-Guclu et al. [6], who demonstrated that inspiratory exercises practised at $40 \%$ of MIP significantly enhanced mental health domains of SF-36 in patients with heart failure.

The last finding of this study was the observed clinically significant reduction in fasting blood glucose from $134 \pm 40$ to $126.8 \pm 51 \mathrm{mg} / \mathrm{dl}$ in the study group. The patients in this group achieved diabetes control, defined by the American Diabetes Association as fasting blood glucose $\leq 130 \mathrm{mg} / \mathrm{dl}$ [32]. This means that although the reduction in fasting blood 
glucose in the study group was not statistically significant, it was clinically meaningful. In turn, after the intervention, fasting blood glucose in the control group was still above the threshold level for diabetes control (i.e. $133 \pm 65 \mathrm{mg} / \mathrm{dl}$ ). Two studies reported significant reductions in blood glucose after inspiratory muscle training in patients with insulin resistance [31] and with fasting hyperglycaemia [33]. The exercise intensity and volume in these studies were higher than in our study. The American Diabetes Association and the American College of Sports Medicine reported that exercise-induced reduction in blood glucose depended on exercise intensity and duration [34]. Thus, if higher exercise intensity and volume were recruited in our inspiratory loaded exercises, a change in fasting blood glucose of both statistical and clinical significance could have occurred. Interestingly, the SF-12 health-related domains and diabetes control are independent outcomes. The mental and physical aspects of the SF-12 Health Survey were not dependent on diabetes control in patients with diabetes [35]. Additionally, no direct relationship between diabetes control and SF-36 physical component scores could be established [36, 37]. Therefore, we cannot attribute the improvements in the SF-12 physical or mental domains to any reduction in the fasting glucose in the study group.

\section{Conclusions}

Low-intensity inspiratory loaded exercises were successful in improving several aspects of diabetes-related QoL as evidenced by improved SF-12 physical health domains and some SF-12 mental health domains in a sample of women with type 2 diabetes. The change in fasting blood glucose in the study group was small and statistically insignificant but otherwise clinically relevant. Health professionals involved in diabetes care may consider these observations. Inspiratory loaded exercises could be a successful alternative to physical exercise therapy when the target is to improve diabetesrelated QoL in type 2 diabetic women unable to take part in physical exercises. However, further studies with a larger sample size are needed to confirm our conclusion.

\section{Disclosure statement}

No author has any financial interest or received any financial benefit from this research.

\section{Conflict of interest}

The authors state no conflict of interest.

\section{References}

1. Kaiser AB, Zhang N, van der Pluijm W. Global prevalence of type 2 diabetes over the next ten years (2018-2028). Diabetes. 2018;67(Suppl. 1); doi: 10.2337/db18-202-LB.

2. Trikkalinou A, Papazafiropoulou AK, Melidonis A. Type 2 diabetes and quality of life. World J Diabetes. 2017;8(4): 120-129; doi: 10.4239/wjd.v8.i4.120.

3. Cai H, Li G, Zhang P, Xu D, Chen L. Effect of exercise on the quality of life in type 2 diabetes mellitus: a systematic review. Qual Life Res. 2017;26(3):515-530; doi: 10.1007/ s11136-016-1481-5.

4. Tymruk-Skoropad K, Tsizh L, Vynogradskyi B, Pavlova I. Physical therapy in chronic obstructive pulmonary disease (analysis of the evidence-based medicine). Physiother Quart. 2018;26(2):1-8; doi: 10.5114/pq.2018.75993.

5. Dall'Ago P, Chiappa GRS, Guths H, Stein R, Ribeiro JP. Inspiratory muscle training in patients with heart failure and inspiratory muscle weakness: a randomized trial. $J$
Am Coll Cardiol. 2006;47(4):757-763; doi: 10.1016/j. jacc.2005.09.052.

6. Bosnak-Guclu M, Arikan H, Savci S, Inal-Ince D, Tulumen E, Aytemir K, et al. Effects of inspiratory muscle training in patients with heart failure. Respir Med. 2011; 105(11):1671-1681; doi: 10.1016/j.rmed.2011.05.001.

7. Palau P, Domínguez E, Núñez E, Schmid JP, Vergara P, Ramón JM, et al. Effects of inspiratory muscle training in patients with heart failure with preserved ejection fraction. Eur J Prev Cardiol. 2014;21(12):1465-1473; doi: 10.1177/2047487313498832.

8. De Medeiros AIC, Fuzari HKB, Rattesa C, Brandão DC, de Melo Marinho PÉ. Inspiratory muscle training improves respiratory muscle strength, functional capacity and quality of life in patients with chronic kidney disease: a systematic review. J Physiother. 2017;63(2):76-83; doi: 10.1016/j.jphys.2017.02.016.

9. Beckerman M, Magadle R, Weiner M, Weiner P. The effects of 1 year of specific inspiratory muscle training in patients with COPD. Chest. 2005;128(5):3177-3182; doi: 10.1378/chest.128.5.3177.

10. Hill K, Jenkins SC, Philippe DL, Cecins N, Shepherd KL, Green DJ, et al. High-intensity inspiratory muscle training in COPD. Eur Respir J. 2006;27(6):1119-1128; doi: 10.1183/09031936.06.00105205.

11. Wu J, Kuang L, Fu L. Effects of inspiratory muscle training in chronic heart failure patients: a systematic review and meta-analysis. Congenit Heart Dis. 2018;13(2):194202; doi: 10.1111/chd.12586.

12. Beaumont M, Forget $P$, Couturaud F, Reychler G. Effects of inspiratory muscle training in COPD patients: a systematic review and meta-analysis. Clin Respir J. 2018;12(7): 2178-2188; doi: 10.1111/crj.12905.

13. Kathe N, Hayes CJ, Bhandari NJ, Payakachat N. Assessment of reliability and validity of SF-12v2 among a diabetic population. Value Health. 2018;21(4):432-440; doi: 10.1016/j.jval.2017.09.007.

14. Pryor JA, Prasad SA (eds.). Physiotherapy for respiratory and cardiac problems: adults and paediatrics, $4^{\text {th }}$ ed. Churchill Livingstone; 2008.

15. Beachey W. Respiratory care anatomy and physiology: foundations for clinical practice, $3^{\text {rd }}$ ed. St. Louis: Elsevier Mosby; 2013.

16. Persing G. Respiratory care exam review, $4^{\text {th }}$ ed. St. Louis: Elsevier Saunders; 2016.

17. Nair R, Kachan P. Outcome tools for diabetes-specific quality of life: study performed in a private family practice clinic. Can Fam Physician. 2017;63(6):e310-e315.

18. Ware J Jr, Kosinski M, Keller SD. A 12-item Short-Form Health Survey: construction of scales and preliminary tests of reliability and validity. Med Care. 1996;34(3): 220-233; doi: 10.1097/00005650-199603000-00003.

19. Al-Shehri AH, Taha AZ, Bahnassy AA, Salah M. Healthrelated quality of life in type 2 diabetic patients. Ann Saudi Med. 2008;28(5):352-360; doi: 10.5144/0256-4947. 2008.352.

20. Michalos AC (ed.). Encyclopedia of quality of life and well-being research. Springer; 2014.

21. De Albuquerque IM, Rossoni CS, Cardoso DM, Paiva DN, Fregonezi G. Effects of short inspiratory muscle training on inspiratory muscle strength and functional capacity in physically active elderly: a quasi-experimental study. Eur J Physiother. 2013;15(1):11-17; doi: 10.3109/21679 169.2013.764925.

22. Cipriano GF, Cipriano G Jr, Santos FV, Güntzel Chiappa AM, Pires L, Cahalin LP, et al. Current insights of 
inspiratory muscle training on the cardiovascular system: a systematic review with meta-analysis. Integr Blood Press Control. 2019;12:1-11; doi: 10.2147/IBPC.S159386.

23. Feriani DJ, Coelho HJ Júnior, Scapini KB, de Moraes OA, Mostarda C, Ruberti OM, et al. Effects of inspiratory muscle exercise in the pulmonary function, autonomic modulation, and hemodynamic variables in older women with metabolic syndrome. J Exerc Rehabil. 2017;13(2):218226; doi: 10.12965/jer.1734896.448.

24. Larson JL, Kim MJ, Sharp JT, Larson DA. Inspiratory muscle training with a pressure threshold breathing device in patients with chronic obstructive pulmonary disease. Am Rev Respir Dis. 1988;138(3):689-696; doi: 10.1164/ajrccm/138.3.689.

25. Zeren M, Demir R, Yigit Z, Gurses HN. Effects of inspiratory muscle training on pulmonary function, respiratory muscle strength and functional capacity in patients with atrial fibrillation: a randomized controlled trial. Clin Rehabil.2016;30(12):1165-1174; doi:10.1177/026921551 5628038.

26. Shahin B, Germain M, Kazem A, Annat G. Benefits of short inspiratory muscle training on exercise capacity, dyspnea, and inspiratory fraction in COPD patients. Int J Chron Obstruct Pulmon Dis. 2008;3(3):423-427; doi: 10.2147/copd.s1822.

27. Ramsook AH, Molgat-Seon Y, Schaeffer MR, Wilkie SS, Camp PG, Reid WD, et al. Effects of inspiratory muscle training on respiratory muscle electromyography and dyspnea during exercise in healthy men. J Appl Physiol. 2017; 122(5):1267-1275; doi: 10.1152/japplphysiol.00046.2017.

28. Jung KM, Bang DH. Effect of inspiratory muscle training on respiratory capacity and walking ability with subacute stroke patients: a randomized controlled pilot trial. J Phys Ther Sci. 2017;29(2):336-339; doi: 10.1589/jpts.29.336.

29. Bailey SJ, Romer LM, Kelly J, Wilkerson DP, DiMenna FJ, Jones AM. Inspiratory muscle training enhances pulmonary $\mathrm{O}(2)$ uptake kinetics and high-intensity exercise tolerance in humans. J Appl Physiol. 2010;109(2):457468; doi: 10.1152/japplphysiol.00077.2010.

30. Lai N, Camesasca M, Saidel GM, Dash RK, Cabrera ME. Linking pulmonary oxygen uptake, muscle oxygen utilization and cellular metabolism during exercise. Ann Biomed Eng. 2007;35(6):956-969; doi: 10.1007/s10439-0079271-4.

31. Silva Mdos S, Martins AC, Cipriano G Jr, Ramos LR, Lopes GS. Inspiratory training increases insulin sensitivity in elderly patients. Geriatr Gerontol Int. 2012;12(2): 345-351; doi: 10.1111/j.1447-0594.2011.00755.x.

32. ADA (American Diabetes Association). Guidelines for glycemic control in people with diabetes. Reprinted with permission from the American Diabetes Association. Clinical practice recommendations 2001. Diabetes Care. 2001;24(1):S34.

33. Dos Santos Silva M, Ramos LR, Tufik S, Togeiro SM, Lopes GS. Influence of inspiratory muscle training on changes in fasting hyperglycemia in the older adult: the Epidoso project. J Diabetes Sci Technol. 2015;9(6): 1352-1353; doi: 10.1177/1932296815599006.

34. Colberg SR, Sigal RJ, Fernhall B, Regensteiner JG, Blissmer BJ, Rubin RR, et al. Exercise and type 2 diabetes: the American College of Sports Medicine and the American Diabetes Association: joint position statement. Diabetes Care. 2010;33(12):e147-e167; doi: 10.2337/dc109990.
35. Riaz M, Rehman RA, Hakeem R, Shaheen F. Health related quality of life in patients with diabetes using SF-12 questionnaire. Journal of Diabetology. 2013;2(1).

36. Weinberger M, Kirkman MS, Samsa GP, Cowper PA, Shortliffe EA, Simel DL, et al. The relationship between glycemic control and health-relation quality of life in patients with non-insulin-dependent diabetes mellitus. Med Care. 1994;32(12):1173-1181; doi: 10.1097/00005650199412000-00002.

37. Lau CY, Qureshi AK, Scott SG. Association between glycaemic control and quality of life in diabetes mellitus. J Postgrad Med. 2004;50(3):189-194. 